(C) Society for Benefit-Cost Analysis, 2016. This is an Open Access article, distributed under the terms of the Creative Commons Attribution licence (http://creativecommons.org/licenses/by/4.0/), which permits unrestricted re-use, distribution, and reproduction in any medium, provided the original work is properly cited.

Joseph Cook*, Peter Kimuyu, Annalise G. Blum and Josephine Gatua

\title{
A Simple Stated Preference Tool for Estimating the Value of Travel Time in Rural Africa
}

\begin{abstract}
Despite its importance in benefit-cost analyses in the water supply, transportation, and health care sectors, there are relatively few empirical estimates of the value of travel time savings (VTT) in low-income countries, particularly in rural areas. Analysts instead often rely on a textbook "rule of thumb" of valuing time at $50 \%$ of prevailing unskilled wage rates, though these benchmarks have little empirical support in these settings. We estimate the value of travel time through the use of a repeated discrete choice stated preference exercise. We asked 325 rural households in Meru County, Kenya to rank two new hypothetical water sources against their current water source. The two new hypothetical sources were described as safe and reliable to use, but varied only in their distance from the household and the price charged per water container. Results from random-parameters logit models imply an average value of travel time of $18 \mathrm{Ksh} / \mathrm{hr}$, and generally support the $50 \%$ rule. These models produce the first individual-level VTT estimates reported in a lowincome setting, and indicate statistically-significant heterogeneity in VTTs, though the heterogeneity is not well correlated with observables. A latent-class approach identifies four classes of respondents: one class (about one third of respondents) values time very highly (49 Ksh/hr), one poorer group values time hardly at all (less than $1 \mathrm{Ksh} / \mathrm{hr}$ ), and two groups value time at approximately $9 \mathrm{Ksh} / \mathrm{hr}$.
\end{abstract}

Keywords: Africa; discrete choice experiment; value of travel time; water supply.

JEL classifications: J22; Q25; Q55.

*Corresponding author: Joseph Cook, Daniel J. Evans School of Public Policy and Governance, University of Washington, USA, e-mail: jhcook@uw.edu

Peter Kimuyu: School of Economics, University of Nairobi, Kenya

Annalise G. Blum: Department of Civil and Environmental Engineering, Tufts University, USA

Josephine Gatua: Department of Economics, University of Gothenburg, Sweden 


\section{Introduction}

The value of travel time savings (VTT) plays a central role in many benefit-cost analyses. The rich literature examining how people trade money and time spent traveling or waiting has focused mainly on route, mode, and speed choices in transportation analysis, or on site choices in analysis of recreational demand for environmental or cultural amenities. Because there are a number of existing studies, benefit-cost analysts usually find that the costs of primary data collection for site-specific VTT estimates outweigh the benefits and instead rely on benefit transfer approaches. In particular, there has developed a consensus toward using several benchmark values expressed as percentages of after-tax wages. For example, one popular textbook (Boardman, Greenberg, Vining \& Weimer, 2010, Table 165, p. 419), citing meta-analyses by Waters (1996) and Von Wartburg and Waters (2004), recommends using 50\% of the after-tax wage rate as the central VTT estimate for commuting or leisure time, $100 \%$ of the wage rate for walking or driving in congestion, and $125 \%$ of the wage rate for waiting.

However, nearly all of these studies have been conducted in industrialized countries. Time savings are an important component of many investment analyses in developing countries, in particular in transportation, labor-saving technologies, access to energy and firewood collection, and water infrastructure access. Analysts in developing countries could choose to transfer these rules of thumb to local wage rates, but the empirical evidence is thin that the rule transfers well from wealthy auto and train commuters to poor rural villagers walking to water, or to slum residents walking along busy highways into the central city. There are in fact relatively few empirical estimates of the value of travel or waiting time in low-income countries - as we discuss in the next section - and estimates vary considerably. Furthermore, reliable secondary data on wage rates and the distribution of income can be difficult to obtain at the local level in low-income countries. Because respondents may not truthfully reveal their true income in surveys, researchers are more likely to rely on constructed wealth indices of observable assets (as we do in this paper). In response, the value of travel time is often reported as a fraction of unskilled wages in "casual" or agricultural labor.

In this paper, we report the results from a simple stated preference experiment on people's willingness to trade time and money in collecting water in rural Kenya. We offered 325 households the hypothetical choice between their current primary water source and two new hypothetical water sources. The new sources differed only in the amount of time needed to collect water and the price charged. We contribute to the literature by adding to the few existing empirical estimates of the value of time in low-income countries. We do, in fact, find support for the benchmark of 
$50 \%$ of unskilled wages. By exploiting the panel nature of the stated preference exercise, the paper is the first (to our knowledge) to report individual-level estimates of the VTT in a low-income country. We use both random-parameters logit and latent-class multinomial logit (MNL) frameworks. We find that models that incorporate heterogeneity in preferences for time and price fit the data better, but that individual-level VTTs are not well correlated with observable characteristics like wealth indices or income.

Furthermore, we demonstrate the "proof of concept" for using this approach, one that is routinely used in transportation studies in rich countries, to low-income settings like ours. The technique is simple and could be easily replicated in other areas of low-income countries to build a better knowledge base of the VTT in lowincome countries. It could be applied in any situation - still unfortunately common across the globe - where people are either bringing water back to the home or paying a "water vendor" to bring it to them. It might also be adapted to the decision to collect or purchase firewood.

The paper has further policy relevance in that it explores the preferences of some of the 748 million people globally without access to "improved" drinking water, over $90 \%$ of whom live in rural areas (World Health Organization \& UNICEF, 2014). In Kenya, the location of our study, only 54\% of rural people have access to improved sources of drinking water, compared to $83 \%$ of urban dwellers. To extend and maintain water supply to rural populations, it is important to understand the relative importance of a water source's cost, quality, distance from home, availability during the day, and its potential for causing conflict with neighbors when used. Given the expense of installing water infrastructure, a particularly important question is how close water points must be for households to use them, and how households trade off proximity with user fees or tariffs that are needed to both expand rural water infrastructure and properly maintain existing facilities.

We proceed by first outlining the existing estimates of VTT in low-income countries, and then describe our study site in rural Kenya and households' existing water supply situation there. Section 4 describes the hypothetical scenario given to respondents and discusses the likelihood that respondents understood it and answered it seriously and carefully. We briefly and verbally sketch our econometric approach in Section 4.1, leaving the details to a supplementary appendix online for interested readers. We then report our VTT results and robustness to a number of different assumptions, and conclude with a summary of the key results and thoughts on replicating the study elsewhere. 


\section{Existing estimates of the value of travel time in low-income countries}

In the transportation sector, two studies in low-income countries have estimated VTTs by examining actual mode choices in a nested logit framework. Dissanayake and Morikawa (2002) report a mean VTT of 27 baht/hr in Bangkok in 1995 (they do not report results as a fraction of wages or income), and Walker, Li, Inivasan and Bolduc (2010) find the implied VTT ranges from 51-86\% of city-wide average income in (urban) Chengdu, China. Liu (2007) adds a stated preference component to revealed mode choices, asking 100 households in Shanghai to rank-order their transportation choices. VTT estimates averaged $64 \%$ of in-sample wage rates for in-vehicle time and $82 \%$ of wages for out-of-vehicle time. Alpizar and Carlsson (2003) use a repeated discrete choice approach similar to ours, asking car commuters in San Jose, Costa Rica to make several hypothetical choices between continuing to commute by car or switching to a public bus. The authors also model data using a random-parameters logit framework, and find mean values of VTT of $40-50 \%$ of the sample's hourly wages, with higher willingness to pay (WTP) for reductions in travel times by bus than by car. Jeuland, Lucas, Clemens and Whittington (2010) applied the travel cost method to households' decisions to travel and wait to receive free cholera vaccines in Beira, Mozambique. Value of travel times, inferred from count models based on the pecuniary cost of travel (bus fares, etc.) implied that respondents valued travel time at $18-46 \%$ of the median hourly wage (Jeuland et al., 2010, Table 2, p.317). Larson, Pienaar, Jarvis and Lovell (2015) use a contingent behavior approach and ask respondents in rural Botswana to make a series of choices among hypothetical jobs in community-based natural resource programs. Each job offer varies by type of activity, daily wage, and days of month to be worked. Larson et al. (2015) use a more flexible model of labor decisions where the shadow value of time varies with a number of economic variables rather than implying a single, constant value of time, and use the model results to estimate reservation wages for each job type. With the exception of Jeuland et al. (2010) and Larson et al. (2015), these studies all survey relatively wealthy residents of urban areas, and none of these studies explored individual-level VTT estimates. Furthermore, comparing VTT estimates across these studies implies that the marginal utility of the activities in question (e.g. sitting in traffic in Bangkok, walking to a vaccination clinic in Beira) are similar. There is little reason to believe that this would be so, rendering the idea of a universal "benchmark" across sectors, modes, and countries somewhat dubious. This argues for more mode- and context-specific estimates such as we provide, and, more generally, better utility-theoretic grounding 
of choice models which incorporate varying (dis)utilities of different activities (Larson \& Lew, 2014).

In the water sector, Whittington, $\mathrm{Mu}$ and Roche (1990) used two methods to value travel time in a small Kenyan town, both of which relied on actual water source decisions. The first bounded VTTs by exploiting differences in collection times (including walking, waiting and filling containers) and prevailing prices paid between free open wells, water kiosks, and water vendors who would deliver water to the house, along with times needed to collect from each of these. The second used an MNL discrete choice framework. Applied to data from 69 households, both approaches found that the value of travel time was approximately $100 \%$ of unskilled wages. Asthana (1997) also analyzed 490 households' water source decisions in rural India using a discrete choice model and found the VTT was approximately $35 \%$ of the unskilled wage rate. Kremer, Leino, Miguel and Peterson-Zwane (2011) examined decisions to travel to springs that had been randomly selected for protection from contamination in rural Kenya. Choices, as well as stated rankings of sources, were modeled with a random-parameters logit framework with a focus on exploring how households valued improvements in quality. To value time, however, the authors used results from a double-bounded, dichotomous choice contingent valuation task. The first version of the task asked households how much they would be willing to pay to "keep their spring" protected. The second version asked households how many minutes they would be willing to walk to access a protected spring. For the 104 respondents with responses to both questions, they divide the willingness to walk by the willingness to pay to derive the VTT, which they estimate has a mean of $\$ 0.088$ per 8 -hr day, or only $7 \%$ of unskilled or casual labor wage rates. Our approach differs from Kremer et al. (2011) in several ways. First, our valuation task explicitly presents respondents with the trade-off between time and money, rather than relying on the ratio of two separate valuation exercises. This also allows us to model responses in a richer random-parameters logit framework and report individual-level VTT estimates. ${ }^{1}$ Finally, the average self-reported oneway walking time in their site was 9 minutes. These are much lower than distances in our site, as we describe below, which may imply that travel time to water is more salient to households in our setting.

1 Kremer et al. (2011) observed only bounded values of time and money and assigned individual values based on the median of a normal distribution fit to the data (see footnote 18, p. 185 of their paper). Only the summary statistics of the distribution of VTT are reported, and the underlying individual-level estimates are not reported or explored. To produce VTT estimates for the remainder of their sample, the paper mentions (p. 185) a regression of these VTT estimates on education, number of children and asset ownership, but the results from this regression are not discussed or presented in the paper or either of the two supplementary appendices. 


\section{Study site and sample}

We interviewed a total of 387 households near the small market town of Kianjai in September 2013, the dry season. Kianjai is approximately 20 miles from the city of Meru, in north-central Kenya. The study site was chosen purposefully because of the large number of existing water source options available; the choice experiment reported here was part of a larger study on rural water source choices. Households were, however, chosen randomly based on a transect approach. More details on the study region and sampling approach are provided in the supplementary appendix online.

A team of seven trained enumerators asked households a number of detailed questions in Meru (the local language) about the water sources that households could use and do use, during both the dry season and the rainy season. The survey asked about distances to all sources, prices charged, trips taken, perceptions of health risk from drinking water from the source, and the likelihood of conflict when using that source. Of these sources, we asked which they used "overall, for most purposes", which we refer to below as their "primary source". The survey also asked about household demographics and socioeconomic status (income, assets, land ownership, etc.). We interviewed the household member "who is mostly responsible for water-related decisions such as where to get water and how much to collect"; this person was also the person "who collected the most water in the past seven days" in three quarters of the cases. Eighty percent of respondents were women.

We interviewed 58 households that had private piped connections inside their compounds and two households that had invested in extensive rainwater collection systems, but drop them from the remainder of the paper because they would have had little reason to take our hypothetical choice of two new water points away from the home seriously. An additional group of 78 households said their primary water source was a private well on their compound. Because these water sources are very close, the households have solved their "quantity" problem, but because the shallow, hand-dug wells are typically unprotected, they are unsafe. Seventy percent of these respondents told us that drinking water from their well posed "some" or "serious" health risk (see Table 2), so the households' water "quality" problem remains. Because respondents are told that our new hypothetical sources would be completely safe to drink, it is plausible that some households with private wells might choose the new, hypothetical source even though it is farther away and has a volumetric price. In some model specifications reported below, we include these respondents, but we begin by focusing on the 247 households that reported either 
walking to collect water from their primary source $(n=237)$ or paying a "water vendor" to bring water to their home $(n=15)$ on a bicycle or cart.

A typical sample household is Catholic and has five members. The household is led by a married couple, both of whom are around forty years old and have each completed seven years of education. They own their house and two acres of land. The household has a private pit latrine, but does not have electricity. Kerosene is used for lighting and firewood is used for cooking and heating. There are two rooms in the main house and three other buildings in the compound. Monthly household income from all sources is approximately 35,000 Ksh or 407 USD. The most common source of income by far is farming. Thirty-nine percent of households, however, had at least one household member who earned income from full-time employment, part-time or seasonal employment, or business and self-employment; roughly $10 \%$ of households had more than one member earning income from these sources. We did not ask about wage rates for each household member separately but rather reported household income, by source, for all members. We calculate implicit wage rates by summing income from these three types of sources, dividing by the total number of household members who work for wages, and dividing by 23 days $* 8$ hours $=184$ hours per month. The median hourly wage rate in the 150 households with these income sources is $33 \mathrm{Ksh} / \mathrm{hr}$; the average is $58 \mathrm{Ksh} / \mathrm{hr}$. Field staff estimated that $35 \mathrm{Ksh} / \mathrm{hr}$ was the most common rate for unskilled manual labor, which fits within our calculated wage estimates.

Average food expenditure is $430 \mathrm{Ksh}$ (5 USD) per household member per week, or a total of 14,924 Ksh (174 USD) per month. Household assets typically include a cell phone, bicycle, and radio, and most households own livestock. Using data on durable assets, electricity connections, sanitation, building characteristics, and cooking fuel, we construct a wealth index using principal component analysis (PCA) following Filmer and Prichett (2001) and Filmer and Scott (2012), and assign households to wealth quintiles. Although water supply variables are often included in wealth indices, we exclude them to avoid potential confounding with other explanatory variables. (The supplementary appendix provides more details on the construction of the wealth index.)

What do people think about their current water sources? This is important not only to understand the site but also because these characteristics will be used as explanatory variables in the discrete choice analysis of the stated preference data. First, the majority know that drinking water from their current "primary source" poses some health risk (Table 2). Although one might think that water brought by a vendor is safer, respondents are aware that vendors often collect from the same unprotected sources. Water from public piped connections is also unsafe because of intermittent pressure and because some systems divert directly from a river without 
Table 1 Household demographics.

\begin{tabular}{lrr}
\hline & Mean & Std Dev \\
\hline Household size & 5.62 & 2.2 \\
Water collectors & 1.72 & 1.5 \\
Female respondent & 0.79 & 0.4 \\
Years of education of female (head of hh or spouse) & 7.09 & 3.7 \\
Has working electricity connection & 0.098 & 0.3 \\
Total monthly income (Ksh) & 17750 & 18769 \\
Weekly food exp. per person (Ksh) & 436 & 327 \\
\hline
\end{tabular}

Note: $N=325$.

treating the water. Second, conflict is a salient feature of their water collection activity. Sixty-six percent of users of a public well say that using the source is likely or very likely to lead to conflict with their neighbors. Private well owners were asked a different question: "has sharing water from your well ever led to conflicts with your neighbors?" Although $27 \%$ said "yes", we assume in our analysis below that using your own private well does not risk conflict. We assume the same for people buying vended water. Third, although water is not always available from sources at convenient times, it is generally accessible. The majority of sources are open 12 hours per day, 7 days a week, or more. We categorize this as "good" availability in Table 2; see table notes for more details. Households who rely primarily on vended water are the most unsatisfied in this regard; forty percent said that service is "irregular" or "unreliable".

Households spend significant economic resources in collecting water. Households purchasing water from sources away from the household pay approximately $2 \mathrm{Ksh}$ per 20L "jerrican"2 (equivalent to USD 0.31 per thousand gallons, or USD 1.16 per cubic meter), and water from vendors costs $10 \mathrm{Ksh}$ per jerrican (Table 3 ). Households walking to get water reported that, on average, it took them 22 minutes to walk home from the source with a full container. These reported estimates are multiplied by 1.75 to get reported round-trip walk times, to account for faster oneway trips with empty containers. Thirteen percent of households reported roundtrip walking times over 1 hour. Households walking to get water reported that they spend 1 hour, on average, waiting to fill their container during an average week in the dry season. We do not know whether households are able to leave jerricans in line and spend the hour doing other tasks; our results below assume they do not.

2 The term jerrican is commonly used to denote rectangular, hard plastic water storage containers, the vast majority of which hold 20 liters of water. 
Table 2 Households' perceptions of their current "primary” water source.

\begin{tabular}{lrrrrrrr}
\hline & $\begin{array}{r}\text { Some } \\
\text { Health } \\
\text { Risk }\end{array}$ & $\begin{array}{r}\text { Serious } \\
\text { Health } \\
\text { Risk }\end{array}$ & $\begin{array}{r}\text { Conflict } \\
\text { some- } \\
\text { what } \\
\text { likely }\end{array}$ & $\begin{array}{r}\text { Conflict } \\
\text { very } \\
\text { likely }\end{array}$ & $\begin{array}{r}\text { Good } \\
\text { avail. }\end{array}$ & $\begin{array}{r}\text { Fair } \\
\text { avail. }\end{array}$ & $\begin{array}{r}\text { Cloudy } \\
\text { or } \\
\text { brown } \\
\text { color }\end{array}$ \\
\hline Private well(78) & 0.44 & 0.26 & - & - & 0.42 & 0.41 & 0.19 \\
Vended(15) & 0.73 & 0.20 & - & - & 0.33 & 0.27 & 0.40 \\
Public well(122) & 0.56 & 0.28 & 0.22 & 0.44 & 0.86 & 0.12 & 0.38 \\
Public borehole(72) & 0.28 & 0.10 & 0.24 & 0.25 & 0.56 & 0.42 & 0.14 \\
Public piped conn(32) & 0.47 & 0.06 & 0.38 & 0.03 & 0.50 & 0.41 & 0.22 \\
Surface, other public(6) & 0.00 & 0.67 & 0.33 & 0.50 & 0.83 & 0.17 & 0.33 \\
\hline
\end{tabular}

Notes: The value in parentheses in the first column is the number of respondents who reported that this type of source was their primary source "overall, for most purposes"; e.g. 78 households reported a private well was their primary water source. Health risks refer to perceived risk from drinking water. "No" health risk is omitted from the table. Conflict refers to the likelihood that "there could be a conflict if you collect from this source in the dry season". Except for private wells and vended water, availability refers to the number of hours per week the source is open for collection; "good" is $12 \mathrm{hrs}$ per day 7 days a week ( $84 \mathrm{hrs)}$ or better. "Fair" is $24-83 \mathrm{hrs}$ per week, and "Poor" is less than $24 \mathrm{hrs}$ per week. For private wells and vended water, availability is "good" if the respondent said the reliability of water from the well (or vendor) is "very regular", "fair" if "regular", and "poor" if "irregular" or "unreliable".

Table 3 Distances (in minutes) and prices for current primary water source.

\begin{tabular}{lcrr}
\hline & $\begin{array}{c}\text { Round-trip }_{\text {walking time }^{\boldsymbol{a}}} \\
\text { wall }\end{array}$ & $\begin{array}{r}\text { Reported dry season } \\
\text { wait times (mins) }\end{array}$ & $\begin{array}{r}\text { Price per 20L } \\
\text { (Ksh) }\end{array}$ \\
\hline Private well(78) & - & 1 & 0.0 \\
Vended(15) & 48 & 1 & 9.7 \\
Public well(122) & 24 & 56 & 2.2 \\
Public borehole(72) & 26 & 54 & 2.2 \\
Public piped conn(32) & 85 & 68 & 2.1 \\
Surface, other public(6) & & 51 & 0.3 \\
\hline
\end{tabular}

Notes: ${ }^{a}$ Round-trip times are 1.75 times the reported one-way walk times with a full container and were estimated for households with private wells based on the reported distance (in meters) between the household and the well, assuming a walking speed of 2.75 kilometers per hour. ${ }^{b}$ Wait times for private wells and vended water are assumed to be 1 minute for filling or the transaction; these were not reported by the household.

\section{Choice experiment}

Immediately after asking households about which of the current sources was their "primary" source, respondents were asked to imagine that two new hypothetical 


\begin{tabular}{|l|c|l|l|}
\hline & $\begin{array}{l}\text { New water } \\
\text { point A }\end{array}$ & $\begin{array}{l}\text { New water } \\
\text { point B }\end{array}$ & $\begin{array}{l}\text { Your current } \\
\text { source }\end{array}$ \\
\hline $\begin{array}{l}\text { Total time to walk to } \\
\text { source, wait, fill container } \\
\text { and return home }\end{array}$ & $\mathbf{1 0 ~ m i n u t e s}$ & $\mathbf{5}$ minutes & $\begin{array}{l}\text { (Time and cost } \\
\text { as reported by } \\
\text { respondent) }\end{array}$ \\
\hline Cost per 20L jerrican & $\begin{array}{c}1 \text { Ksh per } \\
\text { 20L jerrican }\end{array}$ & $\begin{array}{l}\mathbf{0 . 2 5} \text { Ksh per } \\
\text { 20L jerrican }\end{array}$ & \\
\hline
\end{tabular}

Figure 1 Example choice card (translated into English).

water source alternatives were available to them in addition to their primary source. The full translated text of the hypothetical scenario is given in the Appendix. They were told that the water from these new sources would be "excellent and safe for drinking", that the new sources would be open at times convenient for them, and that using the new source would not cause any conflict with their neighbors. The only two attributes that varied between the two new options is the price charged per jerrican and the time it would take to collect water from the source (including time waiting and filling the container). The price and time for the current primary source was based on what the respondent has reported in the prior section for what they characterized as their primary source. The enumerator then showed the respondent the choice task card, explained the attributes associated with each hypothetical new water point, and asked if the respondent had any questions. An example choice task card, translated into English, is shown in Figure 1. Respondents were asked which of the three sources they would most and least prefer to use. The term "preferred to use" was intended to mean the source that the respondent would use exclusively as their primary water source and this is how the question was posed to respondents in the Meru language. We use the most and least preferred data to construct a complete ranking of the two hypothetical choices and the respondent's current primary source.

The experiment was based on a full factorial design of two three-level attributes: a price of $0.25,1$, or $3 \mathrm{Ksh}$ and a total water collection time of 5,10 , or $30 \mathrm{~min}$ utes. These attribute levels were chosen to be lower than average current source prices and collection times so that they would be appealing to respondents. Choice tasks where either hypothetical alternative dominated the other on both time and cost were eliminated, leaving nine choice tasks. These were then divided into three blocks with three choice tasks each. Respondents were randomly assigned to blocks, and task order within the block was randomized. In addition to the three tasks from the block, all respondents were presented with a task (the one depicted in 
Table 4 Patterns of respondent choices.

\begin{tabular}{lrcr}
\hline & $\begin{array}{r}\text { Ranked } \\
\text { dominated } \\
\text { choice } \\
\text { higher }\end{array}$ & $\begin{array}{r}\text { Didn't think } \\
\text { carefully } \\
\text { about SP } \\
\text { exercise }\end{array}$ & $\begin{array}{r}\text { Always } \\
\text { chose status } \\
\text { quo source }\end{array}$ \\
\hline Private well(78) & 0.04 & 0.00 & 0.67 \\
Vended(15) & 0.00 & 0.00 & 0.13 \\
Public well(122) & 0.08 & 0.02 & 0.07 \\
Public borehole(72) & 0.10 & 0.04 & 0.06 \\
Public piped conn(32) & 0.00 & 0.00 & 0.06 \\
Surface, other public(6) & 0.00 & 0.00 & 0.00 \\
All respondents & 0.06 & 0.02 & 0.21 \\
\hline
\end{tabular}

Notes: The sample size is given in parentheses beside the description of current primary source. First column of results based on reported rankings for task where alternative B dominates A - see Figure 1 or Appendix Section A.1. Second column is based on the enumerators' rating of how seriously the respondent took the choice task.

Figure 1) that included one source with the lowest time and lowest price and another source with the middle time and middle price. Because one of the two hypothetical sources dominated the other in both time and price, this task served as a simple comprehension check for the choice experiment. The task was also intended to determine whether the most attractive hypothetical source might tempt households with private wells. The full experimental design is provided in Appendix.

Did respondents understand the exercise and take it seriously? We begin with the comprehension check just described. Recall that respondents gave us a complete ranking of all three alternatives so we can observe which fraction ranked dominated new water point $\mathrm{A}$ higher than new water point $\mathrm{B}$, even if their status quo primary source was their preferred source overall. Only 24 respondents $(6 \%)$ ranked the dominated alternative higher (Table 4). Immediately after the hypothetical exercise, we had enumerators report whether the respondent "thought carefully" about the choices. They felt that $76 \%$ of respondents thought "very carefully", and that only 8 respondents $(2 \%)$ did not think carefully. Finally, $21 \%$ of respondents chose their current primary water source in all four choice tasks; not surprisingly, three quarters of these 69 respondents had private wells at home. For other households that chose their current source, the hypothetical alternatives were in most cases better in all observable dimensions than their current source. Although this could indicate a lack of engagement in the task or status quo bias, it may also simply reflect preferences for their current water source in some other dimension that was not described in the hypothetical scenario. (We also asked respondents about the taste and color of 
the drinking water but omit them from our analysis because of correlations with the health risk variable). Section 5 examines how sensitive results are to excluding respondents who ranked a dominated alternative higher, did not appear to engage seriously, or chose a status quo of inferior observable quality despite not having a well at home.

\subsection{Econometric estimation}

We model the choice between the respondents' status quo water source and the two new hypothetical sources using a standard random utility framework (McFadden, 1974). For brevity, we relegate the details of the model specification to Appendix A2.3. We rely on two econometric approaches: random-parameter logit (RPL) and latent-class MNL. The random-parameters or "mixed" logit (Revelt \& Train, 1998) specification allows us to exploit the panel nature of the repeated hypothetical choices to test for heterogeneity in preferences for distance and price, and thus the value of travel time. The RPL model builds on the simple MNL, sometimes called conditional logit (McFadden, 1974), which assumes one populationlevel coefficient for each attribute and relies on the independence-of-irrelevantalternatives (IIA) assumption. RPL models do not rely on the IIA assumption.

Logic and economic theory suggest that households, in comparing two sources that are the same in all other regards, should not prefer the source that is farther away or more expensive. In other words, the coefficients on price and time should be negative. Random-parameters models incorporate heterogeneity by estimating a fixed population-level coefficient $\beta$ as well as a random disturbance $\sigma_{n}$ around that $\beta$. This disturbance term is often assumed to be normally distributed, which places no a priori sign restrictions on the individual-level coefficient $\left(\beta+\sigma_{n}\right)$ and can lead to models predicting that a certain fraction of respondents have positive cost or time coefficients. Researchers have avoided this problem by assuming a distribution for $\sigma_{n}$ that is truncated or restricted to one domain, typically lognormal distributions. We tested a number of distributions that accomplish this, including lognormal, onesided triangular, Rayleigh, and scaled exponential. Our main results assume the coefficients on price and time are distributed one-sided triangular, though we tested alternative specifications (reported below). Kremer et al. (2011) also assume onesided triangular distributions for distance in their revealed preference model (see Table VI, p. 178). The one-sided triangular distribution assumes the mean and standard deviation are equal, and NLOGIT $^{3}$ restricts the range of the distribution to

3 All RPL models were estimated in NLOGIT5 (Greene, 2012). 
between -1 and 1 (Greene, 2012, p. 543). This forces the distribution to either be entirely positive (all individual-level values between 0 and 1) or entirely negative $\left(-1<\beta_{n}<0\right)^{4}$.

The first set of RPL results uses each of the four choices between hypothetical alternatives A and B and the respondent's current primary water source. We code the price and time attributes for the current primary source as continuous variables based on what respondents told us about those sources (Table 5). Although the SP elicitation was done just after the section where respondents told us about the characteristics of their current water sources and immediately after telling us which was their primary water source, some recall bias of the primary source's characteristics cannot be ruled out. In retrospect, it would have been preferable to write the primary source's characteristics directly on to each of the six choice task cards. We assume that households with private wells face no financial cost for using that well, and impute the time using GIS and the reported distance from the home to the well (predicted round-trip times are all less than 4 minutes and most are under 2 minutes). We use the reported wait times and assume it takes households with private wells 1 minute to fill their container ${ }^{5}$. An alternate-specific constant (ASC) is equal to one if the respondent "opts out" of the hypothetical choices and stays with her primary source (Table 5).

We also include the respondent's perceived health risk, availability, and potential for conflict for the primary source as additional explanatory variables, all effects-coded (see Table 5). Each of these characteristics is interacted with the ASC. The coefficients on this interaction can be interpreted as increasing or decreasing the chance that the respondent opts out. For example, a respondent who reported that her current primary source is very unsafe to drink should be less likely to opt out than a respondent who thinks her current source is safe to drink, all else equal; the coefficient on the interaction should be negative. An alternate approach would be to treat these variables like price and time: respondents were told to assume that the new hypothetical sources were safe to drink, convenient, and pose no risk of conflict, so one could assign them values for risk, conflict, and availability that are all "good" (i.e. -1 for risk and conflict and 1 for reliability). However, this would induce extremely high correlations with ASC, since the hypothetical alternatives always have the same values. We also estimate a model that uses the information contained in the complete ranking of sources.

\footnotetext{
4 More formally, we model price and time as: $\beta_{i}=\beta+\beta v_{i}, v_{i} \sim \operatorname{triangular}(-1,1),(\beta=\sigma)$.

5 Households may value time spent traveling differently than time spent waiting, and may value lower variability in wait times. Although we observe travel and wait times separately for the household's current source, the hypothetical scenario combined the two. Any differences are not identifiable in our stated preference data.
} 
Table 5 Description of primary and hypothetical source attribute variables.

\begin{tabular}{|c|c|c|c|}
\hline Variable & Description & $\begin{array}{r}\text { Hypothetical } \\
\text { source coding }\end{array}$ & $\begin{array}{r}\text { Primary source } \\
\text { coding }\end{array}$ \\
\hline Time & $\begin{array}{l}\text { Round-trip walk } \\
\text { time and waiting }\end{array}$ & 5,10 , or 30 minutes & $\begin{array}{r}1.75^{*} \text { one-way walk time } \\
\text { with full container + wait time }\end{array}$ \\
\hline Price & $\begin{array}{l}\text { Price of 20-liter } \\
\text { jerrican }\end{array}$ & Ksh $0.25,1$ or 3 & $\begin{array}{r}\text { reported price per jerrican for primary } \\
\text { source; } 0 \text { if doesn't pay }\end{array}$ \\
\hline ASC & $\begin{array}{l}\text { Alternate-specific } \\
\text { constant }\end{array}$ & 0 & 1 \\
\hline Health risk & $\begin{array}{l}\text { Perceived risk } \\
\text { from drinking water }\end{array}$ & $\mathrm{N} / \mathrm{A}^{3}$ & $\begin{array}{r}\text { Effects-coded: } \\
=-1 \text { if "no risk" } \\
=0 \text { if "some risk" } \\
=1 \text { if "serious risk" }\end{array}$ \\
\hline Availability & $\begin{array}{l}\text { Hours open and } \\
\text { reliability }\end{array}$ & $\mathrm{N} / \mathrm{A}^{3}$ & $\begin{array}{r}\text { Effects-coded: } \\
=-1 \text { if less than } 24 \mathrm{hrs} / \mathrm{wk} \text { or "irregular" } \\
=0 \text { if } 24-83 \mathrm{hrs} / \mathrm{wk} \text { or "regular" } \\
=1 \text { if }>=84 \mathrm{hrs} / \mathrm{wk} \text { or"very regular" }\end{array}$ \\
\hline Conflict & $\begin{array}{l}\text { Potential for conflict } \\
\text { from using source }\end{array}$ & $\mathrm{N} / \mathrm{A}^{3}$ & $\begin{array}{r}\text { Effects-coded: } \\
=-1 \text { if conflict "not likely at all" } \\
=0 \text { if conflict "somewhat likely" } \\
=1 \text { if conflict "very likely" }\end{array}$ \\
\hline
\end{tabular}

Notes: See notes for Table 2 for more details on health risk, conflict and availability variables. ${ }^{1}$

Predicted walk times used in place of reported times where distance between home and primary source was observed in GIS. ${ }^{2}$ Wait times as reported by households. ${ }^{3}$ Health risk, availability and conflict are all assumed to be excellent for hypothetical sources, but these variables enter only as interactions with ASC to avoid collinearity problems.

The second econometric approach is a latent-class MNL, which uses the panel response data to partition respondents into $c$ classes, where $c$ is specified by the researcher (Roeder, Lynch \& Nagin, 1999). We estimated latent-class models with $c$ varying from 2 to 6 classes and chose models based on the best (lowest) Bayesian Information Criterion (BIC) score. We use a multinomial polytomous logit model to correlate household characteristics to class membership. Latent-class models were estimated in NLOGIT5 (Greene, 2012); the multinomial polytomous logit model was estimated in Stata $12.1^{6}$.

6 We also attempted to estimate "scale" MNL models that assume that heterogeneity in response patterns is due to individual-level differences in the error term, or "scale", rather than preferences. Intuitively, one can think of differences in scale as differences in response "noise" via factors such as how seriously respondents took the task, how well they understood the task, fatigue (from large numbers of 


\section{Results}

\subsection{Random-parameter logit results}

The top panel of Table 6 reports estimated coefficients (utility weights) for the mean $(\beta)$ of randomly distributed parameters as well as the ASC-interaction parameters that are modeled as nonrandom. The bottom panel shows the standard deviation of randomly distributed parameters; significant coefficients here indicate that the preference heterogeneity among respondents is statistically significant. Price and time were modeled as one-sided triangular distributions to restrict them to be in one domain (here negative). Recall that this distributional assumption also restricts the mean and standard deviation to be equal, which is why the coefficients for means and standard deviations are always the same in Table 6. The ASC variable was modeled as normally distributed.

Model A excludes households with private wells but includes respondents who enumerators rated as possibly not thinking carefully about the exercise, who made a preference error by ranking the dominated alternative higher, or who chose their current source on every task. Price and time are strongly significant, and the ASC is negative, indicating an unmodeled propensity to avoid the current primary water source, though not statistically significant.

Model B adds two interaction terms with the ASC parameter and two observable characteristics of the current primary source: the reliability and potential for conflict in using the status quo source. The coefficient on neither interaction is statistically significant. Although the log-likelihood of Model B is slightly better than Model A (as would be expected from adding two additional explanatory variables), Model B performs the same or worse on the two information criteria that penalize the model for these two additional parameters. Here the ASC is negative and statistically significant. Stated differently: there are characteristics of the decision between the current primary source and either of the two hypothetical sources that are not captured by price and time.

Model C includes households with private wells. The coefficients on price and time both increase in magnitude. The distribution on the ASC coefficient is again not statistically significant. Including households with wells, the interactions on

choice sets), lexicographic preferences (i.e. always choose the alternative with the lowest price), or the use of unobserved heuristics to "solve" complicated choice tasks with large numbers of alternatives or attributes. Scale models would not converge on our dataset. We also analyzed the data using a "generalized" MNL (Fiebig, Keane, Louviere \& Wasi, 2010) that nests the random-parameters logit model and the scaled MNL. A model using reported walk and wait times would not converge. However, it had a worse AIC and BIC score than the corresponding RPL model. The scale parameter was not statistically significant, indicating overall that the RPL approach fits the data better. 
Table 6 Random-parameters logit model results.

\begin{tabular}{|c|c|c|c|c|}
\hline & Model A & Model B & $\begin{array}{r}\text { Model C } \\
\text { (include private } \\
\text { wells) }\end{array}$ & $\begin{array}{r}\text { Model D } \\
\text { (incl. wells and } \\
\text { rank data) }\end{array}$ \\
\hline \multicolumn{5}{|l|}{ Means } \\
\hline $\begin{array}{l}\text { Walk + wait time } \\
\text { (Mins) }\end{array}$ & $\begin{array}{r}-0.147^{* * *} \\
(0.014)\end{array}$ & $\begin{array}{r}-0.148^{* * *} \\
(0.015)\end{array}$ & $\begin{array}{r}-0.167^{* * *} \\
(0.015)\end{array}$ & $\begin{array}{r}-0.153^{* * *} \\
(0.0089)\end{array}$ \\
\hline $\begin{array}{l}\text { Price per } 20 \mathrm{~L} \\
(\mathrm{Ksh})\end{array}$ & $\begin{array}{r}-0.757^{* * *} \\
(0.087)\end{array}$ & $\begin{array}{r}-0.763^{* * *} \\
(0.090)\end{array}$ & $\begin{array}{r}-0.842^{* * *} \\
(0.085)\end{array}$ & $\begin{array}{r}-0.686^{* * *} \\
(0.051)\end{array}$ \\
\hline ASC & $\begin{array}{l}-2.02 \\
(1.27)\end{array}$ & $\begin{array}{r}-3.77^{* * *} \\
(1.80)\end{array}$ & $\begin{array}{l}-1.67 \\
(1.08)\end{array}$ & $\begin{array}{r}2.40^{* * *} \\
(0.613)\end{array}$ \\
\hline ASC * Reliability & & $\begin{array}{r}2.16 \\
(1.43)\end{array}$ & $\begin{array}{l}1.76^{*} \\
(1.00)\end{array}$ & $\begin{array}{c}1.80^{* * *} \\
(0.649)\end{array}$ \\
\hline ASC $*$ Conflict & & $\begin{array}{l}-1.41 \\
(0.87)\end{array}$ & $\begin{array}{r}-2.23^{* *} \\
(0.923)\end{array}$ & $\begin{array}{r}0.313 \\
(0.527)\end{array}$ \\
\hline \multicolumn{5}{|c|}{ Standard deviations of random parameters } \\
\hline $\begin{array}{l}\text { Walk + wait time } \\
\text { (one-sided triangular) }\end{array}$ & $\begin{array}{r}0.147^{* * *} \\
(0.014)\end{array}$ & $\begin{array}{r}0.148^{* * *} \\
(0.015)\end{array}$ & $\begin{array}{r}0.167^{* * *} \\
(0.015)\end{array}$ & $\begin{array}{r}-0.153^{* * *} \\
(0.0089)\end{array}$ \\
\hline $\begin{array}{l}\text { Price per } 20 \mathrm{~L} \\
\text { (one-sided triangular) }\end{array}$ & $\begin{array}{r}0.757^{* * * *} \\
(0.086)\end{array}$ & $\begin{array}{r}0.763^{* * *} \\
(0.090)\end{array}$ & $\begin{array}{r}0.842^{* * *} \\
(0.085)\end{array}$ & $\begin{array}{r}-0.686^{* * *} \\
(0.0508)\end{array}$ \\
\hline $\begin{array}{l}\text { ASC } \\
\text { (normal) }\end{array}$ & $\begin{array}{r}8.00^{* * *} \\
(1.21)\end{array}$ & $\begin{array}{r}7.99^{* * *} \\
(1.20)\end{array}$ & $\begin{array}{r}7.53^{* * *} \\
(0.93)\end{array}$ & $\begin{array}{r}5.65^{* * *} \\
(0.493)\end{array}$ \\
\hline Households & 247 & 247 & 325 & 325 \\
\hline Observations & 978 & 978 & 1,288 & 1,288 \\
\hline Log-likelihood & -686.4 & -684.6 & -817.2 & -1470 \\
\hline AIC & 1381 & 1381 & 1646 & 2952 \\
\hline BIC & 1400 & 1411 & 1677 & 2983 \\
\hline BIC (MNL) & 1753 & 1756 & 2234 & 3817 \\
\hline Mean [Median] VTT & $16.7[16.1]$ & $16.8[16.2]$ & $17.1[16.7]$ & $19.4[19.1]$ \\
\hline St. Dev. VTT & 8.43 & 8.48 & 8.13 & 10.6 \\
\hline Mean VTT (MNL) & 14.2 & 16.2 & 12.1 & 11.2 \\
\hline
\end{tabular}

Notes: Standard errors in parentheses. ${ }^{*} p<0.10,{ }^{* *} p<0.05^{* * *} p<0.01$. Simulated maximum likelihood used 1000 Halton draws. Value of travel time (VTT) for the multinomial logit (MNL) model is calculated as $\beta_{\text {time }} / \beta_{\text {price }}$. Mean, median, and standard deviation of the VTT for the RPL models refers to the empirical distribution of individually calculated VTT estimates. 
both reliability and conflict are both statistically significant and of the expected sign: respondents are more likely to select their current primary sources over the hypothetical alternatives when their current source is more reliable and less likely to select their current source when using it is likely to cause conflict ${ }^{7}$.

Model D includes households with private wells as well as the preference information contained in the ranking of all three sources. Using this information implies respondents are somewhat less responsive to price than the other three models, but similarly responsive to distance. The interaction with reliability increases slightly in magnitude and is more strongly significant, though the interaction with conflict is no longer different than zero.

The bottom three rows of Table 6 report the distributional statistics for the implied individual-level estimates of the VTT. These refer to the empirical distribution of individual VTT estimates. Because the triangular distributions restrict the mean and standard deviation to be the same, the means and medians are similar, and these are in turn relatively stable across the four model specifications, as well as a number of specifications not shown. They are also similar, as would be expected, to the single population-level VTT implied by the MNL model, shown in the last row. The mean VTTs in Table 6 are 48\%, 48\%, 49\%, and 55\% of the unskilled manual wage rate of $35 \mathrm{Ksh} / \mathrm{hr}$, and consistent with the "rule of thumb" discussed in the introduction.

The distribution of predicted individual-level VTT estimates is reasonably consistent across the four models. Figure 2 orders respondents based on the implied VTT estimate from Model $\mathrm{C}$ but reports individual-level estimates from all four models, as well as the latent-class model discussed next. (The fact that estimates from Model C appear as a "trendline" is an artifact of sorting on Model C to produce the graph.) The model using the ranking data is less well correlated than the other three models. These VTT estimates are not correlated, however, with reported income, implied wage rates, the PCA-calculated wealth index score, education, the number of water collectors in the home, the age of the main water collector, and whether the main water collector earned wages. Pairwise correlations between each of the four predicted VTTs and these variables were small and not statistically significant at the $10 \%$ level in all but three cases. They are also not correlated with whether the household primarily buys vended water. Purchasing vended water should be a signal that the household values time more highly, though the lack of statistical significance could be driven by the fact that only fifteen households

7 Recall from Table 5 that reliability and conflict are effects-coded. For Model B, a respondent (call her A) with a "very regular" primary source (effects-coded=1), would have an overall mean ASC of -1.67 $($ population mean $)+1.76$ (interaction coefficient $)=0.09$. Respondent B with an "irregular" source (effects-coded $=-1$ ) would have an overall mean ASC of -1.67 (population mean) $+(-1)(1.76)=$ -3.43 . Respondent B is less likely to choose her current primary source than Respondent A. 


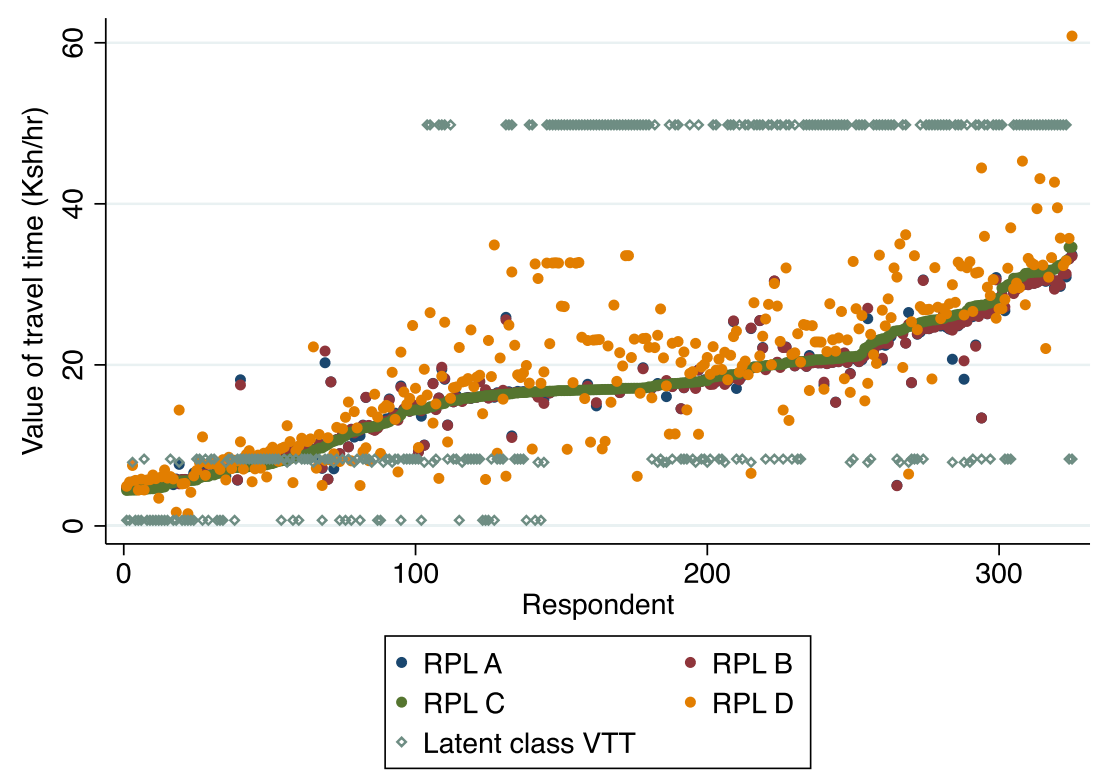

Figure 2 Comparison of value of travel time estimates from RPL models. Notes: Respondents are ordered based on VTT results from Model C Table 6.

relied on vended water as their primary source. The pairwise correlation between estimates from Model D and whether the main water collector was a man was statistically significant but small (-0.12). Households with more water collectors as measured in "adult equivalents", based on nutritional requirements from Collier, Radwan and Wangwe (1986), had lower VTT estimates from Model D (-0.097). Model D estimates were positively correlated (0.16) with the implied average wage rate of the household (significant at the $10 \%$ level).

We explored a number of specifications for testing the sensitivity of our RPL VTT results (see online supplementary appendix Tables A5-A8). The pattern of significance did not change appreciably and the distributional statistics of individual-level VTTs were quite stable when dropping respondents who made a preference error or who were rated as not thinking about the task carefully (Table A5). As expected, however, the coefficients on price and time both increased in magnitude, though their ratio was similar. Results were also similar using a total collection time attribute for the current source based on GIS predictions from geospatial data, rather than reported walk times (Table A6). The estimates for VTT are very similar when estimating the model only on the choice between hypothetical alternative $\mathrm{A}$ and hypothetical alternative $\mathrm{B}$, mitigating some concerns about a status 
quo bias (Table A7). In 55 households, the source that the household reported as their "primary source" was not in fact the source that they had collected the most water from in the past 7 days. Because the hypothetical exercise had primed them to think about whichever source they told us was their main source, we feel the attributes for this reported "primary" source are the most appropriate. Nonetheless, the results are generally similar, and the VTT estimates nearly identical, when we use the attributes for the source they actually collected the most from in the past 7 days (Table A8). We tested a number of specifications of source characteristics interacted with the ASC. In general, these models did not show a constant pattern in significance and sign of the source characteristic interaction terms, though the main results on price, time, and the value of travel time did not vary substantially (results available on request). Finally, models were also estimated for three other distributional assumptions that restrict the price and time coefficients to be negative. Models with lognormally distributed price and time would not converge after multiplying by -1 to restrict them to the positive domain, and models assuming Rayleigh distributions also had inconsistent convergence. Models using a scaled exponential distribution converged and in general had lower log-likelihoods and BICs, but produced skewed distributions of VTT with means on the order of 120 $\mathrm{Ksh} / \mathrm{hr}$, or $350 \%$ of the unskilled wage rate of $35 \mathrm{Ksh} / \mathrm{hr}$, and far higher than the VTT estimates from the simpler MNL model (results available on request).

\subsection{Latent-class models}

We next fit a latent-class MNL model to the choice between the current primary source and the two hypothetical choices. A latent-class MNL uses the panel response data to partition respondents into $c$ classes, where $c$ is specified by the researcher (Roeder et al., 1999). We estimated latent-class models with $c$ varying from 2 to 6 classes and chose a model with four classes because it had the best (lowest) BIC score. These models used data from all respondents, including those with private wells. Table 7 presents the estimated coefficients, the implied VTTs, and the predicted class probabilities.

The model estimates that members in the first class - about one third of respondents - were quite responsive to both price and time, and had a high implied value of travel time ( $49 \mathrm{Ksh} / \mathrm{hr}$, or $140 \%$ of unskilled wages). The negative coefficient on ASC implies, as before, an unmodeled or unobserved propensity to choose one of the two new hypothetical sources.

The second class is very responsive to the price of sources, but much less sensitive to the time cost, implying a very low class VTT (less than $1 \mathrm{Ksh} / \mathrm{hr}$ ). The positive ASC indicates that - time and price equal- respondents are satisfied with 
Table 7 Latent-class multinomial logit model of value of travel time.

\begin{tabular}{lcrrr}
\hline & Class 1 & Class 2 & Class 3 & Class 4 \\
\hline Price & $-2.97^{* *}$ & $-3.07^{* * *}$ & $-0.191^{* *}$ & $-0.716^{* * *}$ \\
Time & $-2.46^{* *}$ & $-0.037^{* * *}$ & $-0.025^{* * *}$ & $-0.099^{* * *}$ \\
ASC & $-5.60^{*}$ & $2.91^{* * *}$ & $2.59^{* * *}$ & $-3.596^{* * *}$ \\
\hline VTT (Ksh/hr) & 49.8 & 0.73 & 7.9 & 8.3 \\
\hline Estimated latent & $(34 \%)$ & $(18 \%)$ & $(16 \%)$ & $(33 \%)$ \\
class probabilities & & & & 107 \\
Respondents & 143 & 46 & & \\
predicted in class & & & & \\
\hline
\end{tabular}

Notes: ${ }^{*} p<0.10,{ }^{* *} p<0.05^{* * *} p<0.01 .{ }^{a}$ Respondents were assigned based on which predicted class probability was highest for that respondent. Value of travel time (VTT) is constant within each class and is calculated as $\beta_{\text {time }} / \beta_{\text {price }}$. A model with 4 classes had the lowest (best) BIC score of models fitted with 2-6 classes; more than 6 classes would not reach convergence. The model presented used 1288 observations from 325 respondents, achieved a log-likelihood of -766 , and had an AIC and BIC of 1561 and 1638.

their primary source. The third and fourth classes were less responsive to both price and time, implying a VTT around $8 \mathrm{Ksh} / \mathrm{hr}$, or roughly $25 \%$ of unskilled wages. The third class has a positive ASC coefficient while the fourth has a negative coefficient.

We estimated a multinomial (polytomous) logit regression to explore socioeconomic correlates of class membership (Table 8). The model fits a maximum likelihood model for a discrete dependent variable (in this case the class which the respondent is predicted to belong to) when there are multiple outcomes for the dependent variable that have no meaningful ordering. (Note this is different than the MNL model discussed earlier, which is often called the conditional logit.) Compared to respondents predicted to be in Class 2 (the omitted category), respondents in Class 1 are more likely to use a private well and be in a higher income quintile. Similarly, respondents in Class 4 are more likely to own wells than those in Class 2 and are less likely to have chosen their current source in all four hypothetical tasks. Classes 2 and 3 are more similar; none of the independent variables in Table 8 predicts membership in Class 3 compared to Class 2. We do not include household-level implied wage rates in the regression because it would drop the majority of households; recall that only $40 \%$ of households have wage income. The pairwise correlation between the latent-class VTT and the calculated wage rates is statistically significant at the $5 \%$ level, though the coefficient is modest $(0.19)$. 
Table 8 Explaining class membership: multinomial (polytomous) logit model.

\begin{tabular}{lrrr}
\hline Variable & Class 1 & Class 3 & Class 4 \\
\hline Private well & $1.24(0.67)^{*}$ & $0.614(0.915)$ & $1.32(0.70)^{*}$ \\
HH members per water collector & $0.008(0.091)$ & $-0.149(0.137)$ & $-0.055(0.0951)$ \\
Income quintile & $0.232(0.130)^{*}$ & $0.217(0.176)$ & $0.209(0.134)$ \\
Health risk (effects-coded) & $-0.292(0.245)$ & $-0.238(0.333)$ & $-0.107(0.248)$ \\
Always chose current source & $0.105(0.581)$ & $-0.237(0.786)$ & $-1.52(0.677)^{* *}$ \\
Ranked dominated alternative higher & $-0.497(0.680)$ & $0.583(0.776)$ & $-0.443(0.721)$ \\
Constant & $0.159(0.488)$ & $-0.690(0.68)$ & $0.477(0.496)$ \\
\hline
\end{tabular}

Notes: $N=325$. Standard errors in parentheses. Test statistic for likelihood ratio test (18 df) is 44.2. The probability that a model with only class constants performs as well as this model: $p=0.0005$.

\section{Conclusions}

Our results present a mixed picture. On one hand, the mean and median estimates of the value of travel time derived from the simple hypothetical exercise are in line with the "rule of thumb" of using $50 \%$ of the unskilled wage rate. These results are robust to the model specifications reported here as well as several not reported. Overall, our results add to the relatively limited knowledge about valuing time in rural areas of poor countries, and support the $50 \%$ rule.

We present the first (to our knowledge) individual-level VTT estimates in a setting like ours using a random-parameters logit framework as well as a latent-class MNL approach ${ }^{8}$. How confident are we that this heterogeneity matters? Results on price and time - the two main attributes of the choice experiment - are stable and consistently statistically significant in models reported here and a number of others (including with scaled exponential and normal distributions) not reported. In all four models, the random-parameters approach fits the data better than a simpler MNL model: moving from the MNL to the RPL model improved BICs and loglikelihoods approximately $30 \%$ in all four models. The individual-level predicted VTTs from the RPL model are not, however, well correlated with observables such as income, a wealth index, wage labor, or the number of water collectors in a household. An agnostic latent-class model divided our respondents into four classes, with one class valuing time very highly, one hardly at all, and two classes in between. Membership in these groups was driven primarily by whether the household's

\footnotetext{
8 We use these results, specifically the latent-class VTT results, to estimate and explore the total "coping costs" of poor water supply in our study site in Cook, Kimuyu and Whittington (2016).
} 
primary water source is a well at home, but class membership was also influenced (encouragingly) by income quintile.

Why might the relationship between VTT estimates and socioeconomic characteristics be weak? First, we cannot rule out that respondents did not think carefully about the exercise and their own current water source options, but, supplementing our robust results on price and time with reports from our enumerators, this seems less likely.

Second, hypothetical bias may also be a concern. Respondents may have treated the hypothetical sources differently, although it is not clear a priori which direction the bias would manifest. In the multiple-task, discrete choice studies examining differences in real versus hypothetical choices which provide "optout" alternatives, the opt-out is a status quo that involves no expenditures (Lusk \& Schroeder, 2004; List, Sinha \& Taylor, 2006; Ready, Champ \& Lawton, 2010; Taylor, Morrison \& Boyle, 2010). The status quo in our study involved the subject's current source, and many respondents were already spending financial resources with that choice. Furthermore, the primary concern in the existing hypothetical bias literature has been that total WTP for the good is overstated, in part because respondents in hypothetical treatments are more like to choose a costly hypothetical alternative (Ready et al., 2010; Taylor et al., 2010), or in the single-choice literature (Cummings, Harrison \& Rutstrom, 1995; Blumenschein, Blomquist, Johannesson, Horn \& Freeman, 2008). This also implies that a hypothetical exercise may overstate the share of respondents who would take up the new hypothetical option. Predicting market share for new water points is not, however, our primary concern. Instead we are interested in VTT, or a marginal WTP value. The evidence for hypothetical bias here is more mixed. Carlsson and Martinsson (2001), in a design with no opt-out alternative, find no difference in marginal WTP in hypothetical and real treatments, though using a similar design Johansson-Stenman and Svedsäter (2008) do. In designs with an opt-out alternative, Lusk and Schroeder (2004) find no difference in marginal WTP for beefsteaks, though Taylor et al. (2010) finds that evidence that marginal WTP estimates for attributes of a public good are much larger in hypothetical treatments (again, both status quo options in these studies involved no expenditures). In summary, it is not clear from prior literature or intuition in which direction hypothetical bias might manifest itself in our VTT estimates. Our mean VTT estimates were, however, relatively robust to (a) models including households with private wells, whom should be less likely to choose a hypothetical source since they were more likely to be satisfied with their current choice, (b) models that use ranks data for all three alternatives, and (c) models that use only information from the choice between the two hypothetical alternatives. Because no data on 
respondent certainty was collected, we cannot use a correction procedure akin to Ready et al. (2010) as a sensitivity analysis.

Third, households may have a different social and practical conception of "time" than those in urban areas in Kenya or in wealthier countries, and may have difficulty both reporting their own current time burdens from water collection and imagining a reduced burden from collecting from the two new sources. The ability to convert time into money is also limited (Larson, 1993) - only 39\% of households in our survey had a member who worked for wages - and highly dependent on the seasonality of farm income.

The stated preference approach reported here could nevertheless be quite useful in empirical research on valuing time use in rural areas of poor countries. It is relatively simple to design and implement, and could be applied to any of the many settings where households are still walking to draw water as well as collect firewood. Unlike other stated preference experiments, strategic bias seems less likely in respondents' answers ${ }^{9}$. The full factorial experimental design could be replicated by changing only the attribute levels to make them appropriate to the study site. Where primary data is already being collected, we estimate that adding this module would add ten minutes at most to the survey length.

Acknowledgments: We thank Mark Mwiti and John Wainana for excellent assistance with fieldwork, data entry, and data analysis. We also thank the editor, two reviewers, Dale Whittington, Greg Characklis, and seminar participants at the University of Colorado-Denver School of Public Affairs and the 8th Annual Meeting of the Environment for Development Initiative for helpful comments and suggestions. We gratefully acknowledge funding support from Environment for Development - Kenya. Cook thanks the School of Public Affairs and the Department of Economics at the University of Colorado for hosting him during a sabbatical stay when much of this work was completed.

9 Strategic bias may show up in our experiment if respondents really wanted to send a signal to policymakers that they wanted the new hypothetical sources built by always choosing the hypothetical source. In this case, one might see only the ASC coefficient, and not the price and time of the alternatives, statistically significant. Also, in models not reported but available on request, we examined only the choice between the two hypothetical alternatives A and B, and price and time remained statistically significant, of similar magnitude, and implied similar mean VTTs. Also, our scenario made clear that cost-recovering prices would be a necessary feature of new handpumps, so households who were not willing to pay for more convenient water sources should have little incentive to overstate demand. 


\section{Supplementary material}

To view supplementary material for this article, please visit http://dx.doi.org/10.10 17/bca.2016.13.

\section{Appendix A. Full text of hypothetical scenario}

"Now I would like you to imagine that a group is planning to install several new water points in your area to improve your access to water. The group could be the government or it could be a nongovernmental organization. These water points could be boreholes or public standpipes from the piped network. If they install only a few water points, people might have to walk further and wait longer to collect water. If they install more, people might walk shorter distances and have to wait less. However, installing these water points is expensive. Suppose 〈the group〉 will need to charge people who use the water points to recover their costs and properly maintain the water points. If they install more points, they may need to charge more per jerrican.

You just told me that the primary source for most purposes right now was 〈primary source from previous question〉. In addition to that source, I want you to imagine you have two new water points available for you to use. You should assume that quality of the water from the new water point is excellent and safe for drinking. You should also assume that the reliability of the new water point would be excellent: it would always have good pressure and you could collect from it whenever it is convenient for you. Finally, you should assume that using the source would not cause any conflict with other water users.

The two new water points differ only in the cost you would have to pay per jerrican, and the total amount of time it would take you to walk to the source, wait, fill your container, and return. Here is the first task I would like you to think about.

If these three sources were available to you right now, which source would you most prefer to use? Remember that the two new sources have excellent quality and reliability, and using them would not cause conflict. Which source would you least prefer to use?" 


\section{A.1 Full experimental design}

\begin{tabular}{|c|c|c|c|c|}
\hline \multirow[t]{2}{*}{ Task } & \multicolumn{2}{|c|}{ Source A } & \multicolumn{2}{|c|}{ Source B } \\
\hline & $\begin{array}{r}\text { Price } \\
(\text { Ksh per 20 L) }\end{array}$ & $\begin{array}{r}\text { Time } \\
\text { (minutes) }\end{array}$ & $\begin{array}{r}\text { Price } \\
(\text { Ksh per 20 L) }\end{array}$ & $\begin{array}{r}\text { Time } \\
\text { (minutes) }\end{array}$ \\
\hline 11 & 0.25 & 10 & 1 & 5 \\
\hline 12 & 0.25 & 30 & 1 & 10 \\
\hline 13 & 3 & 5 & 1 & 30 \\
\hline 21 & 0.25 & 10 & 3 & 5 \\
\hline 22 & 0.25 & 30 & 3 & 5 \\
\hline 23 & 3 & 10 & 0.25 & 30 \\
\hline 31 & 0.25 & 30 & 1 & 5 \\
\hline 32 & 3 & 5 & 1 & 10 \\
\hline 33 & 3 & 10 & 1 & 30 \\
\hline 99 & 1 & 10 & 0.25 & 5 \\
\hline
\end{tabular}

Notes: Blocks are indicated by the leading digit of the task number. Card 99 was answered by all respondents. A respondent in block 1 would answer tasks 11, 12, 13 and 99.

\section{References}

Alpizar, Francisco \& Carlsson, Fredrik (2003). Policy Implications and Analysis of the Determinants of Travel Mode Choice: an Application of Choice Experiments to Metropolitan Costa Rica. Environment and Development Economics, 8, 603-619.

Asthana, Anand (1997). Where the Water is Free But the Buckets are Empty: Demand Analysis of Drinking Water in Rural India. Open Economies Review, 8(2), 139-149.

Blumenschein, Karen, Blomquist, Glenn, Johannesson, Magnus, Horn, Nancy \& Freeman, Patricia (2008). Eliciting Willingness to Pay Without Bias: Evidence from a Field Experiment. The Economic Journal, 118(525), 114-137.

Boardman, Anthony, Greenberg, David, Vining, Aidan \& Weimer, David (2010). Costbenefit Analysis: Concepts and Practices. (4th edn). Upper Saddle River, NJ: Prentice Hall.

Carlsson, Fredrik \& Martinsson, Peter (2001). Do Hypothetical and Actual Marginal Willingness to Pay Differ in Choice Experiments?: Application to the Valuation of the Environment. Journal of Environmental Economics and Management, 41(2), 179-192.

Collier, Paul, Radwan, Samir \& Wangwe, Samule (1986). Labour and Productivity in Rural Tanzania. Oxford UK: Clarendon.

Cook, Joseph, Kimuyu, Peter \& Whittington, Dale (2016). The Costs of Coping With Poor Water Supply in Rural Kenya. Water Resources Research, 52, 841-859.

Cummings, Ronald G., Harrison, Glenn \& Rutstrom, Elisabet (1995). Homegrown Values and Hypothetical Surveys: Is the Dichotomous Choice Approach Incentive-Compatible? The American Economic Review, 85(1), 260-266. 
Dissanayake, Dilum \& Morikawa, Takayuki (2002). Household Travel Behavior in Developing Countries: Nested Logit Model of Vehicle Ownership, Mode Choice, and Trip Chaining. Transportation Research Record, 1805(02), 45-52.

Fiebig, D. G., Keane, Michael, Louviere, Jordan \& Wasi, Nada (2010). The Generalized Multinomial Logit Model: Accounting for Scale and Coefficient Heterogeneity. Marketing Science, 29(3), 393-421.

Filmer, Deon \& Prichett, Lant (2001). Estimating Wealth Effects Without Expenditure Data or Tears: An application to educational enrollments in states of India. Demography, $38(1), 115-132$.

Filmer, Deon \& Scott, Kinnon (2012). Assessing Asset Indices. Demography, 49(April), 359-392.

Greene, William H. (2012). NLOGIT Version 5 Reference Guide. Plainview NY, USA and Caste Hill, NSW, Australia: Econometric Software, Inc.

Jeuland, Marc, Lucas, Marcelino, Clemens, John \& Whittington, Dale (2010). Estimating the Private Benefits of Vaccination Against Cholera in Beira, Mozambique: A Travel Cost Approach. Journal of Development Economics, 91(2), 310-322.

Johansson-Stenman, Olof \& Svedsäter, Henrik (2008). Measuring Hypothetical Bias in Choice Experiments: The Importance of Cognitive Consistency. The BE Journal of Economic Analysis and Policy, 8(1).

Kremer, Michael, Leino, Jessica, Miguel, Edward \& Peterson-Zwane, Alix (2011). Spring Cleaning: Rural Water Impacts, Valuation, and Property Rights Institutions. Quarterly Journal of Economics, 126(1), 145-205.

Larson, Douglas (1993). Separability and the Shadow Value of Leisure Time. American Journal of Agricultural Economics, 75, 572-577.

Larson, Douglas \& Lew, Daniel (2014). The Opportunity Cost of Travel Time as a Noisy Wage Fraction. American Journal of Agricultural Economics, 96(2), 420-437.

Larson, D. M., Pienaar, Elizabeth, Jarvis, Lovell \& Lovell, S. (2015). Wildlife Conservation, Labor Supply and Time Values in Rural Botswana. Environment and Development Economics, forthcoming.

List, John A., Sinha, Paramita \& Taylor, Michael (2006). Using Choice Experiments to Value Non-Market Goods and Services: Evidence from Field Experiments. Advances in Economic Analysis and Policy, 6(2), Article 2.

Liu, Gang (2007). A Behavioral Model of Work-Trip Mode Choice in Shanghai. China Economic Review, 18(4), 456-476.

Lusk, Jayson L. \& Schroeder, Ted (2004). Are Choice Experiments Incentive Compatible? A Test with Quality Differentiated Beef Steaks. American Journal of Agricultural Economics, 86(2), 467-482.

McFadden, Daniel (1974). Conditional Logit Analysis of Qualitative Choice Behavior. In P. Zarembka (Ed.), Frontiers of Econometrics. New York: Academic Press.

Ready, Richard, Champ, Patricia \& Lawton, Jennifer (2010). Using Respondent Uncertainty to Mitigate Hypothetical Bias in a Stated Choice Experiment. Land Economics, 86(2), 363-381.

Revelt, David \& Train, Kenneth (1998). Mixed Logit With Repeated Choices: Households' Choices of Appliance Efficiency Level. Review of Economics and Statistics, 80(4), 647-657.

Roeder, Kathryn, Lynch, Kevin \& Nagin, Daniel (1999). Modeling Uncertainty in Latent Class Membership: A Case Study in Criminology. Journal of the American Statistical Association, 94(447), 766-776. 
Taylor, L. O., Morrison, Mark \& Boyle, Kevin (2010). Exchange Rules and the Incentive Compatibility of Choice Experiments. Environmental and Resource Economics, 47(2), 197-220.

Von Wartburg, Markus \& Waters, William (2004). Congestion Externalities and the Value of Travel Time Savings. In Anming Zhang, Anthony E. Boardman, David Gillen \& William G. Waters (Eds.), Towards Estimating the Social and Environmental Costs of Transport in Canada: A Report for Transport Canada. Chap. 2.

Walker, J. L., Li, Jieping, Inivasan, Sumeeta \& Bolduc, Denis (2010). Travel Demand Models in the Developing World: Correcting for Measurement Errors. Transportation Letters: The International Journal of Transportation Research, 2, 231-243.

Waters, William G. (1996). Values of Travel Time Savings in Road Transportation Project Evaluation. In David A. Hensher, Jenny King \& Tae Hoon Oum (Eds.), World Transport Research: Proceedings of the 7th World Conference on Transport Research. New York: Elsevier.

Whittington, Dale, Mu, Xinming \& Roche, Robert (1990). Calculating the Value of Time Spent Collecting Water: Some Estimates for Ukunda, Kenya. World Development, $18(2), 269-280$.

World Health Organization, \& UNICEF (2014). Progress on Drinking Water and Sanitation: 2014 Update. Tech. rept. Joint Monitoring Programme. 